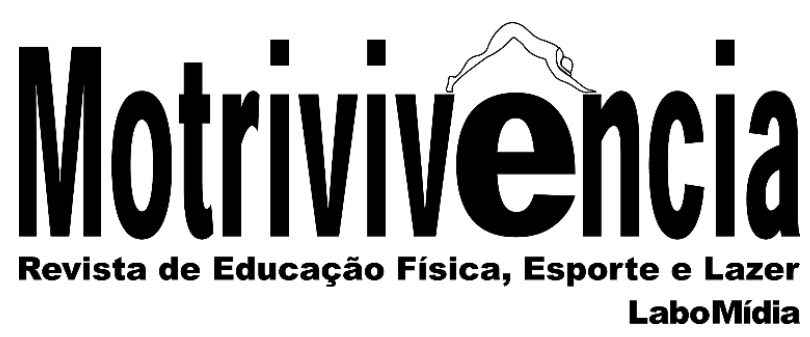

\title{
As representações sociais de universitários de um curso de Educação Física da zona oeste do Rio de Janeiro sobre o jiu-jítsu brasileiro
}

\section{RESUMO}

O objetivo da pesquisa é desvelar e discutir as representações sociais que um grupo de estudantes de graduação em Educação Física possui sobre o Jiu-Jítsu. Portanto, para atingir esse objetivo foi realizada uma pesquisa de campo, tendo sido entrevistados 50 estudantes universitários, sendo 20 do sexo masculino e 30 do feminino. Destarte, as representações sociais compartilhadas entre os universitários são de que o Jiu-Jítsu é uma prática violenta, mas que serve como uma panaceia. Portanto, o estudo concluiu que é necessário a implementação de práticas que impliquem o repensar do esporte de maneira crítica, reflexiva e segura.

PALAVRAS-CHAVE: Psicologia do esporte; Lutas; Esporte
Bernardo de Oliveira Gomes Bacharel em Educação Física Faculdade Gama e Souza - FGS,

Departamento de Biociências,

Rio de Janeiro, Brasil

Bgomes90@hotmail.com

(Dhttps://orcid.org/0000-0003-2674-1838

Jorge Felipe Fonseca Moreira Doutor em Educação Física Centro Universitário Augusto Motta - UNISUAM,

Departamento de Educação Física, Rio de Janeiro, Brasil jorgecoluma@gmail.com (Dhttps://orcid.org/0000-0001-8105-2299

Felipe da Silva Triani Mestre em Humanidades, Culturas e Artes Universidade do Estado do Rio de Janeiro - UERJ, Programa de Pós-Graduação em Ciências do Exercício e

do Esporte,

Rio de Janeiro, Brasil

felipetriani@gmail.com (Dhttps://orcid.org/0000-0001-6470-8823 


\title{
The social representations of university students of a Physical Education course in the western zone of Rio de Janeiro on the brazilian jiu-jitsu
}

\begin{abstract}
The objective of the research is to unveil and discuss the social representations that a group of undergraduate students in Physical Education has over Jiu-Jítsu. Therefore, to achieve this goal, a field survey was carried out. Fifty university students were interviewed, of which 20 were male and 30 were female. Thus, the social representations shared among university students are that Jiu-Jitsu is a violent practice, but serves as a panacea. Therefore, the study concluded that it is necessary to implement practices that involve the rethinking of the sport in a critical, reflexive and safe way.
\end{abstract}

KEYWORDS: Sports psychology; Fights; Sport

\section{Las representaciones sociales de los estudiantes universitarios de un curso de Educación Física en la zona occidental de Río de Janeiro sobre el jiu-jitsu brasileño}

\section{RESUMEN}

El objetivo de la investigación es desvelar y discutir las representaciones sociales que un grupo de estudiantes de graduación en Educación Física posee sobre el Jiu-Jítsu. Por lo tanto, para alcanzar ese objetivo se realizó una investigación de campo, habiendo sido entrevistados 50 estudiantes universitarios, siendo 20 del sexo masculino y 30 del femenino. De ahí que las representaciones sociales compartidas entre los universitarios son de que el Jiu-Jitsu es una práctica violenta, pero que sirve como una panacea. Por lo tanto, el estudio concluyó que es necesario la implementación de prácticas que impliquen el repensar del deporte de manera crítica, reflexiva y segura.

PALABRAS-CLAVE: Psicología del deporte; Luchas; Deporte 


\section{INTRODUÇÃO}

A história e tradição do Jiu-Jítsu são contadas e vividas há mais de dois mil anos, graças as suas raízes no Ju-jitsu japonês e remontada a partir de sua chegada ao Brasil, onde a filosofia transformou-se no estilo de vida da família Gracie, sobretudo por influência dos irmãos Carlos e Hélio Gracie (ROBBE, 2006). Esses mestres contribuíram de maneira significativa para ressignificar o Ju-Jítsu e dar-lhe uma nova roupagem, fazendo emergir uma prática diferenciada intitulada Jiu-Jítsu Brasileiro que carrega consigo características próprias. Essa luta é pautada em suas raízes, um alicerce moral, baseado no respeito, passagem de valores, ética e disciplina entre mestre e discípulos, sendo compartilhada pelos pares a partir da denominação "arte suave" (GRACIE, 2007).

Nessa esteira, eventos como Ultimate Fighting Championship (UFC) e PRIDE Fighting Championships contribuíram para a disseminação das Mixed Martial Arts (MMA) e consequentemente disseminação do Jiu-Jítsu Brasileiro pelo mundo, isto é, internacionalização do modelo ressignificado no Brasil. A luta brasileira também se manifestou como oportunidade de emprego e de mercado, pois uma grande quantidade de escolas e academias foi instituída (RUFINO; DARIDO, 2010).

Na década de 2000 o Jiu-Jítsu Brasileiro foi tratado como temática em várias matérias de jornais de grande circulação, como "Folha de São Paulo" (RUFINO; DARIDO, 2010). Porém, o problema foi à associação instituída pela mídia entre praticantes de Jiu-Jítsu e brigas de rua, algo que implicou, ainda nesse período, a cristalização de representações sociais do Jiu-Jítsu Brasileiro que contraria os preceitos da "arte suave". Então, os praticantes da luta por ocasião das violências urbanas causadas por pessoas que se intitulavam lutadores, foram estigmatizados, fazendo emergir, ainda na década de 2000, a figura do "pit boy", que era o nome atribuído aos praticantes de Jiu-Jítsu Brasileiro que brigavam nas ruas (RUFINO; DARIDO, 2009; RUFINO; DARIDO, 2010).

A Teoria das Representações Sociais proposta por Moscovici (2012) constitui um referencial teórico que tem as representações sociais como objeto de estudo, sendo assim, utilizá-la para compreender como os grupos sociais se comportam diante de determinados objetos representacionais não é raro. Nessa perspectiva, por ser a teoria fundamentada em conceitos da área de comunicação, Moscovici (2012) afirma que as representações sociais são conhecimentos compartilhados sobre um determinado objeto que as pessoas engendram a partir da comunicação interpessoal e entre grupos, fato esse que o faz propor a teoria no âmago da Psicologia Social, pois 
as representações sociais perpassam psicossocialmente, uma vez que estão tanto no âmbito individual como no coletivo.

De acordo com o propulsor da teoria, é necessário compreender dois mecanismos que estão no seio de qualquer representação social, a saber: ancoragem e objetivação. O primeiro faz referência ao núcleo figurativo, ambiente subjetivo na consciência que faz o sujeito associar uma imagem a uma ideia, isto é, ocasião em que o sujeito busca em referências simbólicas e subjetivas que já constam na sua experiência de vida como: fatos históricos presentes na memória, momentos vivenciados ou alguma imagem da lembrança que consiga associar ao objeto a ser representado. Já o segundo ocorre quando o objeto identificado no núcleo figurativo é associado ao objetivo e compõe uma representação social, no caso do Jiu-Jítsu, quando o sujeito associa a imagem das brigas de rua, instituído pela comunicação midiática, ao praticante de Jiu-Jítsu (TRIANI, 2015).

As associações dos praticantes de Jiu-Jítsu aos brigões de rua que se intitulam lutadores foram identificados em um estudo anterior (RUFINO; DARIDO, 2010). Nele, foram entrevistadas dez pessoas sem experiência prévia na modalidade, mas que já tinham algum tipo de contato. $\mathrm{Na}$ ocasião, como resultado foi identificado que a maioria dos entrevistados relatou conhecer o Jiu-Jítsu Brasileiro por meio de eventos específicos informados por mídias de grande circulação que o caracterizaram de forma pejorativa, pois a notícia vinculava condutas ilegais à praticantes de JiuJítsu.

Uma investigação anterior (MELO et al., 2015) também mostrou que há uma tensão recorrente no âmago das lutas, discutindo a questão de quem deve ministrar aulas de luta, se é o mestre na modalidade ou o profissional de educação física, com graduação e registrado no conselho profissional. Diante desse cenário, é possível tecer alguns questionamentos: a pesquisa de Rufino e Darido (2010) mostrou que não praticante possuem uma visão estigmatizada do Jiu-Jítsu Brasileiro, porém, será que estudantes de educação física que atuarão com a Educação Física e com o Esporte possuem uma visão crítica sobre a luta ou ainda que estudantes e futuros profissionais compartilham das representações sociais como os não praticantes? Portanto, considerando essa questão norteadora, foi realizada uma investigação com o objetivo de conhecer e discutir as representações sociais que um grupo de estudantes de graduação em educação física possuem sobre o Jiu-Jítsu Brasileiro.

\section{MATERIAL E MÉTODOS}


O delineamento metodológico empregado para atingir aos objetivos da investigação adotou a pesquisa exploratória na perspectiva de Severino (2007), cuja função é proporcionar maior familiaridade com o problema o explicitá-lo, envolvendo levantamento bibliográfico e entrevista. Adicionalmente, o estudo de campo foi empregado como procedimento técnico.

Nesse contexto, inicialmente foi realizado um levantamento bibliográfico em livros e nas bases indexadoras Google Acadêmico e SciELO. Dessa maneira, a investigação foi realizada a partir dos seguintes descritores: "Jiu-Jítsu”, “Jiu-Jítsu brasileiro”, “brazilian Jiu-Jítsu", "valores”, "esporte", "luta", "arte marcial" e "representações sociais", em diferentes ordens e combinações, sendo incluídos os artigos originais e de revisão sobre a temática.

Para composição do estudo houve a colaboração de estudantes universitários do curso de Educação Física de uma faculdade particular na zona oeste do Rio de Janeiro, sujeitos da investigação. A escolha foi realizada por critério de aproximação, de maneira convencional, aleatória e não probabilística, sendo a amostra composta por 20 pessoas do sexo masculino e 30 do sexo feminino de diferentes períodos, com média de idade de 26 anos, totalizando 50 indivíduos. Cabe assinalar que três dos entrevistados possuíam disseram ter experiências prévias com a modalidade, pois praticaram quando criança ou adolescente.

Os procedimentos, em síntese, para este estudo foram de abordagem qualitativa (MATTOS, 2016), tendo a entrevista como instrumento de coleta de dados. A coleta se deu na forma de entrevistas individuais e a aplicação do instrumento consistiu em criar estímulos para que o entrevistado compartilhasse seus conhecimentos sobre o Jiu-Jítsu.

Após a coleta de dados, todas as entrevistas foram transcritas para um banco de dados e analisadas com base no método de análise de conteúdo proposto por Bardin (2009). O método permitiu a criação de duas categorias, a saber: "a construção social da violência no esporte" e "o esporte panaceia". Essas categorias permitiram a inserção do conteúdo das entrevistas estabelecendo um contraponto com a discussão vigente na literatura sobre a temática.

O estudo foi aprovado pelo Comitê de Ética em Pesquisa da Universidade do Grande Rio, sob guarda do CAAE de número 61550916.1.0000.5283 e realizado com aprovação dos discentes dos cursos de Educação Física envolvidos após assinatura do Termo de Consentimento Livre e Esclarecido (TCLE).

\section{RESULTADOS E DISCUSSÃO}




\section{A Construção Social da Violência no Esporte}

O esporte espetáculo parece permear as representações sociais que os universitários têm sobre diferentes modalidades, não seria diferente com o Jiu-Jítsu que hoje está presente em revistas, no canal do You Tube e outras mídias digitais, assim como um canal específico para as lutas na TV por assinatura. Nesse tipo de esporte a lesão é um acometimento que está presente e até predominante quando se fala em esporte de alto rendimento. Eventos como UFC, Bellator, Jungle Fight e outros, que parece atuar principalmente a espetacularização da violência, implica o surgimento de representações sociais do Jiu-Jítsu enquanto prática lesiva, prática sangrenta. Dessa maneira, o conteúdo das falas parece desvelar representações sociais de que o Jiu-Jítsu Brasileiro é uma prática perigosa. Essas representações sociais coadunam com as de luta compartilhada na mídia televisiva, sobretudo no UFC e suas cenas sangrentas, como se observa nas falas dos universitários.

Acho um esporte bastante perigoso e lesivo à saúde dos alunos [...] (UNIVERSITÁRIO 1).

É um esporte no qual se deve ter um grande conhecimento e durante a prática devese tomar algumas precauções para não lesionar seu parceiro de treino (UNIVERSITÁRIO 10).

Acho legal, mas tenho medo de me lesionar por isso não faço (UNIVERSITÁRIO 20).

De acordo com Arruda e Souza (2014), a televisão alimenta uma visão negativa sobre a prática das lutas, pois divulga uma imagem sensacionalista sobre ela, com objetivo de conquistar maior audiência a qualquer custo, lógica da espetacularização, que norteia algumas práticas esportivas, sobretudo o futebol e o MMA.

Um dos motivos responsáveis pela associação do Jiu-Jítsu à violência foi o fato de algumas pessoas que praticavam brigas generalizadas em praias, bairros e boates serem intituladas de praticantes de Jiu-Jítsu. Em trecho de matéria de jornal (RUFINO; DARIDO, 2010) é anunciado que lutadores de Jiu-Jítsu são acusados de provocar brigas em Franca. O aumento do número de matérias desse gênero fez surgir uma figura muito famosa pelas confusões de rua, trata-se do "pit boy" (RUFINO; DARIDO, 2009). Portanto, a notícia vendida associando o fato criminoso ao JiuJítsu, implica a emergência de representações sociais de que a luta é uma prática violenta, algo que, não condiz com a sua finalidade, pois um de seus objetivos é a de superação do mais forte pelo mais fraco (ARRUDA; SOUZA, 2014). 
Outro caso que merece destaque é a rixa entre os lutadores de Jiu-Jítsu e os lutadores de luta livre que extrapolaram por muitas vezes os certames esportivos e terminaram em confrontos sangrentos e até uso de armas (ALONSO, 2017). Fatos como este apontam para um ensino dissociado da filosofia formativa das artes marciais, sendo assim, os comportamentos de briga e violência não condizem com os ensinamentos filosóficos e doutrinários das artes marciais, pautados em sistemas religiosos como o Confucionismo, Taoísmo e Budismo (2015). No entanto, alguns indícios de representações sociais que associam o Jiu-Jítsu as brigas e violência, ilustradas na metáfora "pit boys" ainda se encontram presente no discurso dos entrevistados:

É uma luta que serve para defesa pessoal de uma forma excelente, mas geralmente (a maioria dos praticantes) é vista de uma forma marginalizada por causa dos brigões de festas [...] (UNIVERSITÁRIO 35).

Não conheço, apenas ouço falar. Porém não posso generalizar, mas parece um esporte violento e o que ouvi foi que pessoas que praticam agem de forma violenta (UNIVERSITÁRIO 50).

O que parece é que os "pit boys" usam as lutas, principalmente o Jiu-Jítsu, no caso da zona sul do Rio de Janeiro (ALONSO, 2017), para aprimoramento de uma técnica para brigar na noite carioca. Vale ressaltar que, sobretudo, nos anos 1990 e 2000 o Jiu-Jítsu entrou na moda e muitos gostam de dizer que praticam a luta que notabilizou a família Gracie nos diversos embates ao longo da história (SERRANO, 2016). Contudo, preocupado com essa imagem estigmatizada, o campeão Rillion Gracie atribui o mau uso do Jiu-Jítsu à proliferação de academias, muitas vezes, sem controle da confederação e da federação. Nesse sentido, afirma que "infelizmente muitos professores desconhecem a história do Jiu-Jítsu, sendo assim, estão despreparados para poder ministrar as aulas. O esporte permite que estravasse o estresse de forma saudável, seu valor é justamente este, melhorar a vida das pessoas" (SERRANO, 2016, p. 17).

Além disso, Serrano (2016) aponta que as artes marciais, quando passam pelo processo de aculturação no Brasil, acabam perdendo um pouco de sua essência oriental, que é o respeito e a disciplina, para ingressar em uma lógica ocidental fragmentada dos valores disciplinares herméticos que marcam as lutas orientais. Nesse sentido, o autor reforça que se for para seguir fidedignamente a disciplina tão difundida por mestres como Jigoro Kano ${ }^{1}$, Funakoshi $^{2}$ e Ueshiba ${ }^{3}$ um "pit boy" não aguentaria mais do que três aulas e abandonaria devido às questões normativas.

\footnotetext{
${ }^{1}$ Fundador do Judô e responsável pela reforma do Jujitsu.

${ }^{2}$ Mestre responsável pelo Karatê Shotokan.

${ }^{3}$ Mestre do Aikido.
} 
No entanto, lamentavelmente, alguns professores e também praticantes contribuem para esse estado, acentuando uma visão distorcida sobre o Jiu-Jítsu, sobretudo por demonstrarem desconhecimento de sua origem e propagação como esporte. A partir do momento em que se pratica a luta sem os critérios assumidos em sua origem, isto é, a prática desvinculada dos valores, a filosofia do Jiu-Jítsu é subvertida e se institui, por meio de grupos ou sujeitos isolados, procedimentos reprováveis como a violência (COELHO et al., 2016).

A experiência prática nas regras milenares, vivenciada na luta, permite algumas modificações psicossociais. De acordo com Gracie (2007), o Jiu-Jítsu brasileiro, na sua concepção, tem como objetivo formar e contribuir na extração de rótulos atribuídos às pessoas, como "franzino", "apavorado", "frouxo", “inseguro" e "indefeso". Na certeza de que o praticante conquistaria autoconfiança e coragem para enfrentar a vida cotidiana, isto é, uma maneira de adquirir segurança.

Quando a pessoa é apresentada a alguma luta e o processo formativo respeita os princípios filosóficos, por meio da prática, acredita-se na mudança de sua conduta. Quando o estudo é mais aprofundado, percebe-se que são transmitidos valores que evidenciam a essência e o praticante entende o que ele está fazendo. Como exemplificado nas palavras do Universitário 44:

No início eu tinha muito preconceito, porque me baseava na opinião dos outros e pelo que eu simplesmente visualizava. Até que um dia recebi um convite de fazer uma aula experimental e me apaixonei, aquele preconceito virou amor, e traz diversos benefícios para saúde física e espiritual (UNIVERSITÁRIO 44).

Os grandes lutadores se aperfeiçoam em várias modalidades de lutas, e uma modalidade que não pode ficar de fora é a luta de imobilizações (ALONSO, 2017). Sendo assim, aumenta a procura do Jiu-Jítsu Brasileiro, criando um estereótipo que o Jiu-Jítsu é praticado apenas por pessoas que visam sobressair-se nos torneios de MMA (GUIMARÃES, 1998). Eventos que vêm conquistando espaço na mídia, como o UFC, que televisionam situações de corpos ensanguentados na ocasião de uma disputa que nasce para verificar qual a luta mais eficiente em um combate real (ALONSO, 2017).

Neste sentido, a brutalidade televisionada parece vender não uma imagem de esporte, mas um espetáculo escarlate que remete às antigas arenas romanas que apascentavam a insatisfação do povo com o sangue dos gladiadores, algo que Vargas e Carvalho (2016) intitularam de "Gladiadores da Pós-Modernidade". Não alheio a isso, o narrador Galvão Bueno em uma transmissão de MMA para o canal aberto Rede Globo chama os lutadores em questão de gladiadores do terceiro milênio 
(ALONSO, 2017). Indícios dessas representações sociais podem ser observada no conteúdo das falas dos entrevistados:

Acho que deveria ser um tipo de luta só para homens, pois é muito pesado (UNIVERSITÁRIO 18).

Acho um pouco intenso para a parte feminina (UNIVERSITÁRIO 27).

A fala dos sujeitos da pesquisa sugere uma censura ligada à violência e outras ao gênero das pessoas que devem consumir esse tipo de produto. Desvela indícios de representações sociais de que a luta é entendida pelos universitários entrevistados como uma atividade direcionada para o público masculino. Nesse contexto, em uma pesquisa anteriormente publicada (ROMERO, 2001), ao entrevistar professores e alunos de educação física ainda na escola, percebeu que os professores separavam meninos de meninas nas atividades da aula, fato não estranho para quem ministra aulas de educação física há mais de 20 anos e infelizmente ainda presente em alguns espaços de prática.

Além disso, o estudo apontou que na concepção dos meninos, a presença das meninas na atividade era algo desnecessário, pois segundo eles o fato de elas não terem habilidades desenvolvidas nas atividades praticadas por eles, elas deveriam fazer outra coisa. Portanto, percebese que a questão de ter "atividades para meninos" e "atividades para meninas" está presente mesmo na escola.

De acordo com Mocarzel e Columá (2015) a ideia de que a mulher não pode praticar lutas e artes marciais, pois as mesmas são atividades masculinas e por esse motivo elas ficariam masculinizadas, trata-se de uma questão ideológica ligada ao imaginário socialmente construído de associa a mulher às princesas dos contos de fada, sereias e bonecas, isto é, a metáfora do "sexo frágil". No entanto, além da questão imaginária, os autores também denunciam o fato de que há falta de adaptação das técnicas para o sexo feminino e ainda do fato de haver treinos exclusivamente femininos, criados a partir de situações de praticantes que não respeitavam as mulheres, chegando até mesmo a ocorrência de abuso sexual.

No que concerne ao esporte midiático, Mourão (2001) exemplifica o caso de Maria Lenk, Yara Vaz e Aída dos Santos como mulheres ícones que foram capazes de modificar representações sociais sobre a mulher no esporte. Em estudo anterior (MOURÃO, 1996), a mesma autora já tecia uma discussão nesse sentido, mostrando que a participação da mulher no esporte, ainda nos anos de 1950, constituía uma representação social que depunha contra sua feminilidade e os Jogos da Primavera era, de certa maneira, um contraponto ao imaginário da época. 
Além disso, essas e outras pesquisas foram realizadas apontando a questão da mulher no esporte, em alguns casos ilustrando representações sociais que a pessoa do sexo feminino deveria ser praticante de natação ou tênis (MOURÃO, 1996), que os cargos da gestão do esporte deveriam ser ocupados por pessoas do sexo masculino (OLIVEIRA; VOTRE, 2009) e ainda que quando uma mulher obtinha resultados expressivos em competições esportivas sua feminilidade era duvidosa, pois seu resultado era "masculino" (DEVIDE; VOTRE, 2000). No entanto, embora a questão das mulheres no esporte já tenha sido muito discutida nas atividades de luta, a não representatividade das mulheres parece ainda existir, embora existam casos isolados, como o de Ronda Hussey, atleta de UFC que conquistou o cinturão e ascensão da mulher perante o universo midiático e da luta. Amanda Nunes e Cris Ciborgue seguem esses passos no universo das lutas mistas.

Em se tratando do Jiu-Jítsu como atividade física, o mesmo se apresenta como uma prática de ganho à saúde. Entretanto, muitas vezes em sua prática, quando se fala em estereótipo, o praticante de Jiu-Jítsu é percebido como aquele sujeito com "orelhas estouradas" e em alguns casos, indivíduos emocionalmente descontrolados e que "gostam de brigar", algo que, trata-se de uma fragilidade de caráter que pode ocorrer em qualquer indivíduo e contexto social. No entanto, as implicações físicas também surgem no conteúdo da resposta de um dos sujeitos da pesquisa:

Acho legal, mas tenho medo de ficar com a orelha de lutador. Mas tenho vontade sim de fazer e acho bem bacana (UNIVERSITÁRIO 24).

Com relação às marcas deixadas devido à prática, a exemplo das "orelhas estouradas" (ruptura da cartilagem), nem todos os praticantes as têm. Portanto, marcas podem ou não acontecer. Isto irá variar de praticante para praticante. São consequências da atividade sistemática e ocorrer no Jiu-Jítsu (ARRUDA; SOUZA, 2014). Além da aparência física, outro elemento que está presente nas palavras dos respondentes é o contato físico intenso. Como exemplificado nas palavras abaixo:

Acho um pouco agressivo, e muito agarramento (UNIVERSITÁRIO 28).

Não tenho interesse por ser uma luta muito juntinha (UNIVERSITÁRIO 46).

Não acho interessante porque é uma luta que as pessoas ficam grudadas, prefiro dar socos, chutes e etc. (UNIVERSITÁRIO 47).

A questão do contato físico intenso pode ilustrar indícios de representações sociais no sentido de que o "agarramento", como faz referência os entrevistados, não caracteriza a essência da prática, mas sim uma questão metodológica que varia de acordo com o ambiente de prática (MOCARZEL; COLUMÁ, 2015). De acordo com Arruda e Souza (2014), esse elemento surge em 
estudos anteriores como "agarra-agarra de machos", isto é, uma representação social que está presente no senso comum, e pode ser explicitada nas marcas linguísticas "luta juntinha" e "pessoas grudadas", que sugerem uma debilidade no sentido de "macheza" que pode ser cristalizada e associada à figura do personagem do programa de televisão Casseta e Planeta da Rede Globo, o Massaranduba, que ao menor sentido de "desvio da representação social de macheza", ele vinha com seu bordão: “está duvidando de minha masculinidade? Vou dar Porrada!”.

Porém em outro prisma, Gracie (2007) explica que o sistema de luta no solo, elemento presente nas falas dos universitários como "agarramento", acontece devido ao fato de que a luta praticada no solo reduz o distanciamento entre o "forte" e o "franzino", pois a luta no chão poderia equilibrar e dar possibilidades maiores para o "franzino" submeter o aparente mais forte.

Guimarães (1998) acrescenta que, o Jiu-Jítsu, enquanto técnicas de defesa pessoal, bem como no conhecimento de alavancas e aplicação destas em pontos vulneráveis do corpo humano, aliado às noções de equilíbrio, multiplica substancialmente a força inicial, permitindo ao mais fraco defender-se e até dominar um adversário fisicamente mais forte, vindo a fortalecer o pensamento do mestre Helio Gracie que sempre declarou que o Jiu-Jítsu é a luta do fraco contra o forte (GRACIE, 2007).

\section{O Esporte Panaceia}

Inicialmente e algo que emerge em grande quantidade dos conteúdos das entrevistas é o termo "disciplina”, embora seja um valor presente nas lutas orientais, também está presente no JiuJítsu. O termo, da maneira que surge no conteúdo das entrevistas, parece ser uma panaceia.

Pratiquei essa luta até meus 16 anos e acho muito boa com a disciplina, educação e o respeito para com todos. O Jiu-Jítsu me fez um homem melhor e colocarei meus filhos no Jiu-Jítsu para que tenham uma melhor qualidade de vida (UNIVERSITÁRIO 36).

Em minha opinião o Jiu-Jítsu e um esporte muito importante na cultura brasileira. Os brasileiros foram conhecidos mundialmente pela pratica do Jiu-Jítsu. Além de disciplinar as crianças ajuda também no gasto energético (UNIVERSITÁRIO 32).

Disciplina, determinação, educação, formação do cidadão, livra das drogas e é um meio de promover saúde e qualidade de vida (UNIVERSITÁRIO 2).

Admiro muito, Já pratiquei quando criança e teria muita vontade de voltar a praticar. Aprendemos muito a ter disciplina respeito ao próximo e adquirimos mais responsabilidades (UNIVERSITÁRIO 37). 
No que tange à questão comportamental, é possível identificar alguns indícios em explicações históricas. Conhecer o Jiu-Jítsu, no que se refere ao seu surgimento e transformações, assim como em outras modalidades de luta, é fundamental para que se possa entender a prática enquanto objeto didático e educativo (GUIMARÃES, 1998). No entanto, embora a luta contribua substancialmente para a formação do sujeito, há nas palavras dos entrevistados indícios de representações sociais de que o esporte retira as pessoas de práticas ilícitas ou de má conduta, algo que, o esporte pode contribuir, mas é fundamental saber que não se trata de uma prática de causa e efeito.

De acordo com Gracie (2007), a prática do Jiu-Jítsu pensada pela família de mesmo nome é aquela em que o franzino, apavorado, frouxo, inseguro e/ou indefeso aprende a sair de situações de covardia e começa a conhecer seu potencial, isto é, praticar a transcendência de limites. O mesmo autor argumenta que o Jiu-Jítsu propagado pela família Gracie não foi desenvolvido para atletas, mas para pessoas aprenderem a se defender. Esse apontamento desconstrói as representações sociais de que a prática do Jiu-Jítsu serve como uma panaceia.

No entanto, esses indícios de representações sociais do Jiu-Jítsu Brasileiro como panaceia, além de estar ancorado na vivência dos entrevistados, parecem possuir raízes históricas. De acordo com Virgílio (2002), o Jiu-Jítsu tradicional de grande influência japonesa, era praticado pelos samurais, isto é, pelas figuras mais éticas que habitavam o Japão durante a era do shogunato. Fato que se fragiliza com o fim desta era. Nessa perspectiva, o fundador do Judô, Jigoro Kano, ministro da cultura do Japão e praticante do antigo Ju-jitsu, antecessor do Jiu-Jítsu, teve como preocupação o resgate do Bushido (Código de Honra dos Samurais), a fim de religar a prática corporal às religiões orientais e fundamentar uma filosofia para a arte. Dessa maneira, as práticas de etiqueta foram inseridas em rituais como: as formas de cumprimento ao Sensei, ao Dojô e aos companheiros.

Kano (2008) ressalta que quando a pessoa é ensinada no caminho de alguma arte marcial que tem princípios filosóficos orientais, existem boas chances de acontecer mudanças de conduta no praticante. No entanto, o estudo da arte precisa ser aprofundado em uma intensidade que transmita segurança em afirmar que a prática do Jiu-Jítsu realmente provoca mudanças atitudinais em seus praticantes.

Porém existem possibilidades reais de mudança de condutas no sentido que os ensinamentos pregados na prática da arte marcial podem ser resultados ou metáforas de uma filosofia pautada na disciplina oriental que busca uma elevação espiritual e não apenas uma busca performática, valores religiosos amalgamados a valores esportivos tendem a marcar o corpo e o caráter do praticante. Nesse sentido, Kano (2008) merece destaque ao difundir valores ressignificados do Ju-jitsu reunidos no Judô que ganha o mundo e se torna um dos poucos esportes de luta praticados nas 
olimpíadas modernas. Cabe ressaltar que é fundamental costurar discussões do Jiu-Jítsu Brasileiro com o Judô, ainda que o texto tenha o Jiu-Jítsu brasileiro como objeto de estudo, pois o mesmo não é uma fórmula vazia e embora tenha passado pelo processo de ressignificação no Brasil, suas raízes ainda se encontram no antigo Ju-jtsu.

Em outra perspectiva, o esporte também pode ser praticado com fins relacionados à saúde, embora não tenha uma relação de causa e efeito diretamente, como é representado pelos entrevistados:

É um esporte muito legal, pois da muita disciplina para as pessoas e é um bom método para emagrecer (UNIVERSITÁRIO 29).

Ótima atividade física, disciplina, eleva a autoestima melhora a conduta pessoal (UNIVERSITÁRIO 40).

Um esporte muito completo que agrega disciplina e qualidade de vida ao praticante (UNIVERSITÁRIO 4).

Um ótimo esporte para o desenvolvimento da coordenação, disciplina, saúde (UNIVERSITÁRIO 9).

Nesse cenário, se percebe as contribuições do Jiu-Jítsu como atividade física, que vão além do gesto técnico. Ele possui benefícios ao atuar no sistema cardiorrespiratório, sistema muscular, flexibilidade, alongamentos e coordenação motora, mas também contribui no aspecto mental para o autocontrole, combate o estresse e oportuniza o convívio social (ARRUDA; SOUZA, 2014).

Rufino e Martins (2011) entrevistaram 15 participantes de um projeto social de Jiu-Jítsu com o objetivo de analisar o impacto de um projeto de Jiu-Jítsu na promoção da cidadania. Como resultado, obtiveram que os sujeitos demonstraram gostar muito da prática da modalidade e afirmaram que o mesmo se apresenta como uma alternativa salutar para a prática de atividade física. Gehre e seus colaboradores (2010) também conduziram uma investigação, a fim de comparar a aptidão física em adolescentes praticantes e não praticantes de Jiu-Jítsu. A amostra foi composta por 25 alunos que foram divididos em 3 grupos, sendo praticantes iniciantes, praticantes avançados e não praticantes. Então, após realizar os testes a pesquisa concluiu que a participação dos adolescentes na modalidade Jiu-Jítsu contribuiu no aumento das capacidades relacionas à força e os indicadores aumentam conforme o tempo de prática, além disso, os praticantes também se mostraram beneficiados com o efeito protetor da atividade sobre a pressão arterial. Portanto, logicamente, quando os estudantes atribuem o processo de emagrecimento à pratica do esporte, trata-se, portanto, de uma representação social, pois o esporte contribui para esse processo, porém, em essência, não tem essa função como fim. 
Outro item que surge na fala de uma das pessoas entrevistadas é a questão de préhabilidades, como se pode observar no discurso do Universitário 23:

Uma arte linda e complexa que exige do praticante astucia e destreza (UNIVERSITÁRIO 23).

Um estudo realizado com lutadores de Jiu-Jítsu brasileiro (VECCHIO et al., 2007), com títulos recentes, fez uma bateria de testes motores e percebeu que os atletas dessa modalidade necessitam de alta força isométrica e componente aeróbio destacado para manutenção do combate. No entanto, o estudo foi realizado com atletas e, sendo assim, fica evidente que profissionais necessitam de alguns requisitos para serem o que são, porém, para praticar o exercício do Jiu-Jítsu não é necessária nenhuma habilidade a priori.

\section{CONCLUSÃO}

A conclusão da pesquisa aponta que, para os universitários do curso de Educação Física o Jiu-Jítsu Brasileiro é uma atividade violenta e perigosa, mas também uma panaceia, um bálsamo curador para alguns males da presente era. As representações sociais sobre a modalidade, no que se refere à violência e perigo, estão ancoradas em fatos históricos como brigas de rua da década de 2000, isto é, à figura do "pit boy" que legou de maneira indolente a imagem da luta no Brasil, tendo sido reforçada pelo discurso midiático.

Por outro lado, os discursos também apontam a luta como uma espécie de panacéia, como se a pessoa que fosse iniciada na modalidade, consequentemente, fosse inserida no caminho dos bons costumes, uma atividade de causa e efeito. Essas representações sociais parecem estar ancoradas em experiências de infância e/ou enquanto praticante na modalidade ou em alguma outra, havendo, nesse caso, uma associação mais próxima da filosofia marcial, embora não a faça, de fato.

Portanto, faz-se necessário proporcionar reflexões críticas para esses estudantes, a fim de repensar a maneira pela qual representam o esporte, pois enquanto profissional de educação física formador de opinião é importante combater essas representações sociais que aviltam e depõem contra o Jiu-Jítsu brasileiro. Adicionalmente, considerando as limitações do presente artigo, sugerese que mais intervenções nos campos científicos e interventivos sejam desenvolvidas para combater as representações sociais que vêm sendo compartilhadas sobre os esportes de luta. 


\section{REFERÊNCIAS}

ALONSO, Marcelo. Por trás do octógono. Rio de Janeiro: PVT, 2017.

ARRUDA, Pablo Delano Porfílio; SOUZA, Bertulino José de. Jiu-Jítsu: uma abordagem metodológica relacionada à quebra de estereótipos. Revista RedFoco, v. 1, n. 1, p. 67-89, 2014.

BARDIN, Laurence. Análise de conteúdo. Lisboa: Edições 70, 2009.

COELHO Milton de Souza; COELHO Paulo Renato; SALGADO FILHO, Leandro Nogueira; COLUMÁ, Jorge Felipe; TRIANI, Felipe da Silva. O samurai como metáfora da sociedade japonesa. Revista Kinesis, v. 34, n. 2, p. 83-101, 2016.

DEVIDE, Fabiano Pries; VOTRE Sebastião Josué. A representação social de nadadores másters campeões sobre a sua prática competitiva da natação. Revista Brasileira de Ciências do Esporte, Brasília, v. 21, n. 2, p. 56-64, 2000.

GEHRE, José Augusto Vieira et al. Aptidão física de alunos do ensino médio praticantes e não praticantes de Jiu-Jítsu. Revista Brasileira de Ciência e Movimento, Brasília, v. 18, n. 2, p. 76-83, 2010.

GRACIE, Hélio. Gracie Jiu-Jítsu. Saraiva: São Paulo, 2007.

GUIMARÃES, Fernando. Metodologia Educacional do Jiu-Jítsu. Rio de Janeiro: Mimeo, 1998.

KANO, Jigoro. Judô Kodokan. Pensamento: São Paulo, 2008.

MATTOS, Rafael da Silva. Pesquisa Qualitativa em Educação Física. Curitiba: CRV, 2016.

MELO, Wellington Eneas; TRIANI, Felipe da Silva; DORIA Carlos Henrique; CHAVES Simone Freitas; COLUMÁ, Jorge Felipe. Tradição x Formação: tensões no campo profissional da capoeira. Corpus et Scientia, v. 11, n. 2, p. 95-108, 2015.

MOCARZEL, Rafael; COLUMÁ, Jorge Felipe. Lutas e artes marciais: aspectos educacionais, sociais e lúdicos. SUAM, 2015.

MOSCOVICI, Serge. A Psicanálise, sua imagem e seu público. Petrópolis: Vozes, 2012.

MOURÃO, Ludmila. Mulheres que ignoraram tabus e alteraram representações nas atividades físico-desportivas. In: VOTRE, Sebastião Josué (Org.). Imaginários e Representações Sociais em Educação Física, Esportes e Lazer. Ed. Gama, 2001, p. 195-214.

MOURÃO, Ludmilla. A imagem da mulher esportista nos Jogos da Primavera dos anos 50. In: VOTRE, Sebastião Josué (Org.). A representação social da mulher na Educação Física e no Esporte. Rio de Janeiro: UGF, 1996, p. 61-78.

NOVIKOFF, Cristina. Dimensões Novikoff: um constructo para o ensino e aprendizagem na pesquisa. In: ROCHA, José Geraldo da; NOVIKOFF, Cristina (Orgs.). Desafios da práxis 
educacional à formação humana na contemporaneidade. Rio de Janeiro: Espalhafato comunicações, 2010.

OLIVEIRA, Gabriela Aragão Souza de Oliveira; VOTRE, Sebastião Josué Votre. Assimetria de gênero na distribuição das mulheres na gestão esportiva. In: XVI Congresso Brasileiro de Ciências do Esporte e III Congresso Internacional de Ciências do Esporte. Salvador, BA. 2009.

ROBBE, Mauricio. Jiu-Jítsu: Arte suave. São Paulo: On Line, 2006.

ROMERO, Elaine. Os estereótipos, as representações sociais, as questões de gênero e as repercussões sobre o corpo. In: VOTRE, Sebastião Josué (Org.). Imaginários e Representações Sociais em Educação Física, Esportes e Lazer. Ed. Gama, 2001, p. 173-194.

RUFINO Luiz Gustavo Bonatto; DARIDO Suraya Cristina. Considerações iniciais sobre o jiu jitsu brasileiro e suas implicações para a prática pedagógica. Anais do Congresso Paulistano de Educação Física Escolar, Caraguatatuba: CONPEFE, 2009.

RUFINO, Luiz Gustavo Bonatto; DARIDO, Suraya Cristina. O jiu jítsu brasileiro na visão dos não praticantes. Coleção Pesquisa em Educação Física, v. 9, n. 2, p. 181-188, 2010.

RUFINO, Luiz Gustavo Bonatto; MATINS, Carlos José. O jiu jitsu brasileiro em extensão. Revista Ciência em Extensão, v. 7, n. 2, p. 84-101, 2011.

SERRANO, Marcial. O livro proibido do Jiu-Jítsu: a história que os Gracies não contaram. 2016.

TRIANI, Felipe da Silva. As representações sociais de estudantes de educação física sobre o corpo. 113f. Dissertação (Mestrado em Humanidades, Culturas e Artes). Universidade do Grande Rio, 2015.

VARGAS, Angelo Luis de Souza; Carvalho Pedro Guedes de. Gladiadores da Pós-Modernidade? Um estudo sócio-jurídico sobre os eventos de MMA. Rio de Janeiro: autografia, 2016.

VECCHIO, Fabricio Boscolo Del et al. Análise morfo-funcional de praticantes de brazilian Jiu-Jítsu e estudo da temporalidade e da quantificação das ações motoras na modalidade. Movimento \& Percepção, v. 7, n. 10, p. 263-281, 2007.

VIRGÍLIO, Stanlei. Conde Koma: O invencível yodan da historia. Átomo: Campinas, 2002.

\section{NOTAS DO AUTOR}

\section{AGRADECIMENTOS}

Os autores agradecem aos estudantes que participaram da pesquisa.

\section{FINANCIAMENTO}

Não se aplica.

\section{CONSENTIMENTO DE USO DE IMAGEM}

Não se aplica. 


\section{APROVAÇÃO DE COMITÊ DE ÉTICA EM PESQUISA}

A pesquisa foi aprovada pelo Comitê de Ética em Pesquisa da UNIGRANRIO, sendo o número do parecer 2.072.798, com data de 19 de maio de 2017.

\section{CONFLITO DE INTERESSES}

Não há conflito de interesses.

\section{LICENÇA DE USO}

Os autores cedem à Motrivivência - ISSN 2175-8042 os direitos exclusivos de primeira publicação, com o trabalho simultaneamente licenciado sob a Licença Creative Commons Attribution Non-Comercial ShareAlike (CC BY-NC SA) 4.0 International. Estra licença permite que terceiros remixem, adaptem e criem a partir do trabalho publicado, desde que para fins não comerciais, atribuindo o devido crédito de autoria e publicação inicial neste periódico desde que adotem a mesma licença, compartilhar igual. Os autores têm autorização para assumir contratos adicionais separadamente, para distribuição não exclusiva da versão do trabalho publicada neste periódico (ex.: publicar em repositório institucional, em site pessoal, publicar uma tradução, ou como capítulo de livro), com reconhecimento de autoria e publicação inicial neste periódico, desde que para fins não comerciais e compartilhar com a mesma licença.

\section{PUBLISHER}

Universidade Federal de Santa Catarina. Programa de Pós-Graduação em Educação Física. LaboMídia - Laboratório e Observatório da Mídia Esportiva. Publicado no Portal de Periódicos UFSC. As ideias expressadas neste artigo são de responsabilidade de seus autores, não representando, necessariamente, a opinião dos editores ou da universidade.

\section{EDITORES}

Mauricio Roberto da Silva, Giovani De Lorenzi Pires, Rogério Santos Pereira.

\section{HISTÓRICO}

Recebido em: 31 de março de 2018.

Aprovado em: 01 de julho de 2018. 